\title{
The recent history of the treatment of asthma: a personal view
}

\section{JOHN MORRISON SMITH}

It is difficult to appreciate today the feeling of helplessness I remember just over 30 years ago when, having recently obtained a senior appointment, I was consulted by an intelligent young man with severe asthma. He had failed to respond to bronchodilators and his distress was such as to threaten his otherwise happy and successful family and business life. It was apparent to me, and to him, that my scanty teaching on the subject as an undergraduate and even 11 years' experience in practice had not prepared me for this problem. I did not lack interest in respiratory disease or indeed in allergy. I had developed hay fever myself while a medical student and had some difficulty in finding anyone who knew what it was. This seems very curious in retrospect, for now hay fever is a matter of common knowledge. I do not think that any of my teachers were aware of the experimental researches on the cause and nature of hay fever published by Charles Blackley in 1873 . His book describing his careful work associating hay fever with grass pollen was almost certainly long out of print when I was a student. It was reprinted in 1959.' Today asthma is one of the commonest conditions seen in chest clinics and I wonder where all these patients went 30 or 40 years ago. Journals concerned with respiratory disease now print many articles related to asthma but this was not always so.

Asthma has gained literary respectability owing mainly, in my view, to advances in treatment. Much the same thing happened with tuberculosis.

Death is another stimulus to interest and when writing about this in $1966^{2}$ I was conscious that I would probably precipitate other work-such as that of Speizer and others in $1968^{3}$ and many others after them. Some of the relative lack of interest before about 1966 could be explained by the common belief and teaching that asthma was very rarely fatal. The possible association between unexpected deaths in young asthmatics and overuse of isoprenaline aerosols was also giving rise to considerable interest at the time. In retrospect we can see that deaths from chronic bronchitis and emphysema also rose in the $1960 \mathrm{~s}$, but the rise in deaths from asthma in young people caused most interest. We have never had an entirely convincing explanation of this temporary phenomenon although we have not lacked theories. ${ }^{45}$

Address for reprint requests: 3 Pantycelyn, Fishguard, Dyfed SA65 9EH.

\section{Early experience in drugs}

My undergraduate teaching about asthma was minimal. The drugs available were adrenaline and ephedrine, which were popular, and aminophylline and isoprenaline, which were less popular. I also remember Brovon, a combination of adrenaline, atropine, and papaverine, which is still used. Neither Brovon nor any similar preparations, originally delivered by nebulisers operated by a simple hand bulb, were to my knowledge suspected of being harmful or likely to be overused. Isoprenaline solution cost very little and almost the only practical problem was that the little glass nebuliser parts tended to become blocked and could easily be broken. The patient needed to keep at least one replacement available. In the past stramonium leaf and potassium nitrate were inhaled either by burning them in a dish or smoking them in an "asthma cigarette." Such asthma cigarettes were certainly available in chemists' shops 40 years ago. They apparently gave short-lived relief and seem to reflect the poverty of effective remedies in the period. Many curious proprietory remedies were sold, some of which still exist and remain popular with certain patients.

Although adrenaline dated back to the experiments of the physiologists Oliver and Schäfer at the end of the last century on extracts of the adrenal gland ${ }^{6}$ it was probably undervalued for many years, but it had become widely used in acute asthma by my student days. Going back a bit further, Berkhart in $1911^{7}$ clearly preferred morphine for acute asthma, and even Cooke in $1923^{8}$ wrote that "morphine acts more slowly, but more thoroughly, and is of the greatest use when the attack is fully developed and refuses to yield to any ordinary measures." $\mathrm{He}$ went on to say that "there is not the easy return to normal after morphine that sometimes obtains after adrenaline." Such ideas may be slow to go completely and it was not until after I was in practice that I truly appreciated the dangers of morphine and other sedatives in acute asthma. Measurement of blood gases in hospital is relatively recent but increased awareness of this risk has resulted from blood gas measurement.

Sir Henry Dale and his colleagues showed that many but not all of the symptoms exhibited by the guinea-pig with anaphylaxis could be produced by histamine. The associations between histamine and 
allergy have proved to be genuine but to some extent misleading. When antihistamine drugs were first introduced into clinical practice by Bernard Halpern in $1942^{10}$ expectations were high. I myself had hopes that my recurrent torture from hay fever could be ended, but like many others I was disappointed. Sir Henry Dale himself (fig 1) in his opening address to the fourth European Congress of Allergy in $1959^{\circ}$ warned us not to draw too hasty conclusions from his work and that of others regarding the mechanism of the immediate allergic reaction and the relevance of experiments in animal species to disease in man. It is wrong to dismiss antihistamines entirely, however. They are still used in mild cases, especially in childhood, with some effect at times and, of course, they have value in conditions other than asthma.

\section{Specific treatment}

I do not recall any teaching about the specific treatment of allergic asthma, although I may have had some advice about avoiding domestic pets and flowers. This is perhaps unusual since hyposensitisation treatment had been introduced for hay fever

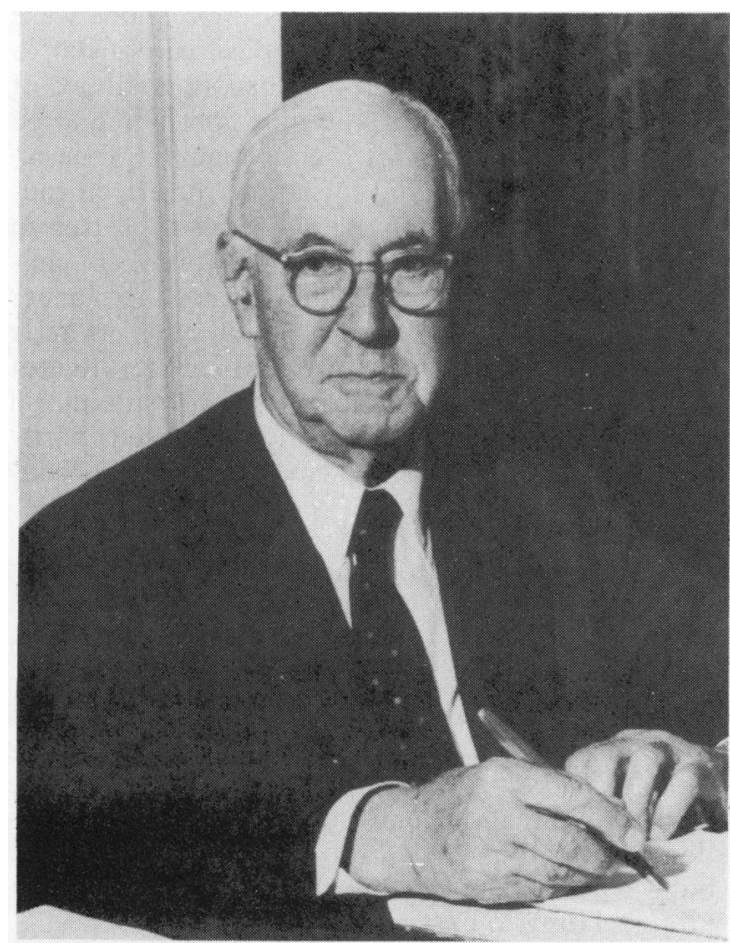

Fig 1 Sir Henry Dale. and pollen asthma in 1911 by Leonard Noon ${ }^{11}$ (fig 2 ). The original idea was that hay fever, being an idiosyncratic reaction to a toxin in grass pollen, could be controlled by producing an antitoxin as a result of repeated small inoculations of pollen extract. This mistaken oversimplification was understandable in the climate of that time, when great advances were being made in the control of bacterial infection. Undoubtedly hopes were raised, which to a large extent went unfulfilled and led to a reaction of ill-informed scepticism about allergic disease. My student teaching of 40-45 years ago was probably influenced by this climate of opinion. Had I graduated elsewhere it might have been different, for John Freeman, Noon's collaborator, had established a large allergy clinic at St Mary's Hospital in London attended by hundreds of patients who received desensitisation. Freeman lived to a great age and I remember his attending meetings of the British Allergy Society in the 1950 s. It was not until this period that this work affected my own clinical practice. Noon and Freeman treated patients with aqueous extracts of pollen, giving graduated doses and claiming reduction in symptoms and in the sensitivity of the conjuctiva to pollen extract. Both local and

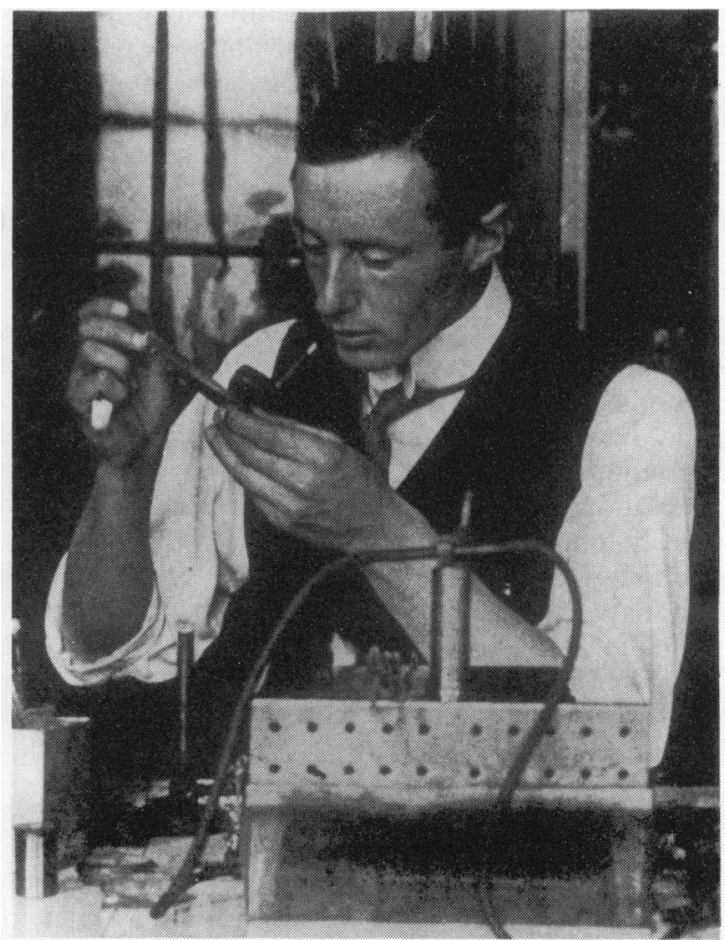

Fig 2 Leonard Noon. 
general reactions occurred. In the early 1950 s I used very long courses of similar aqueous extracts, obtained commercially. They were of essentially two types, grass pollen extract and house dust extract. I also used some mould extracts, mainly those of Cladosporium herbarum, but I did not use the complicated extracts made up from the many substances to which the patient reacted on skin testing. My course of injections was based on skin-test results and on a clinical history. After a few years I gradually abandoned this method of treatment, perhaps more from a general disillusionment than as a result of the clinical trials which I had carried out myself and others reported in the journals. I had an impression that after long courses of weekly injections some patients began to get local reactions lasting a week or more and also suffered clinical deterioration. Was an undesirable antibody being produced? The object was to block the allergic reaction, not to enhance it. Measurements of "blocking antibody" vary from the simple skin test of Kate Maunsell ${ }^{12}$ to measurements of histamine release from cells and immunoglobulin assays. The skin test method consisted of mixing serial dilutions of the patient's own serum with a fixed amount of allergen extract and doing a series of intradermal skin tests. It could thus be shown that the patient's serum at a certain concentration would inhibit the skin reaction and must therefore contain a "blocking antibody." This was heat stable whereas the reagenic antibody giving the passive transfer reaction was heat labile. This "blocking antibody" was produced by a course of hyposensitisation, but did not bear any relation to clinical improvement.

Interest in food allergy has a very long history and has always had its devotees. In my early years these were few but recently this interest has been increasing with the possibility of blocking allergic reactions in the gut by pharmacological means. Foremost among the early enthusiasts was Albert Rowe, who had been drawn to this subject by his personal experience of illness precipitated by foods. His exclusion diets contained many recipes which could be helpful and very pleasant. Most clinicians, although aware of the occasional patient with dramatic immediate reactions to food, were reluctant to accept that the methods used by such enthusiasts could have a wide application in asthma. Possibly the practical difficulties also acted as a deterrent.

\section{Psychological aspects and treatment}

When I was a student in the late 1930 s and for many years afterwards asthma was considered by many of the most influencial medical teachers to be largely psychosomatic in origin. Such an attitude towards a disease reflects a lack both of understanding of the basic mechanisms in the pathogenesis and of effective treatment. Much was written about the emotional aspects of tuberculosis long after the tubercle bacillus had been identified but before specific treatment was available. Even as late as 1964, at a meeting on the nature of asthma, Dr DA Williams and his colleagues considered that psychological factors played a part in the causation of $70 \%$ of the 487 cases studied, although in only $1.2 \%$ did they consider the cause to be entirely psychological. ${ }^{13}$

This attitude towards asthma, a chronic condition which undoubtedly gave rise to emotional distress, was transmitted not only to doctors at an early and impressionable stage in their lives but also to patients and their families. The impression, not usually expressed directly, that the patient was in some degree responsible for the distress of his own illness was widespread. It may have been most evident with children, and as more effective treatment became available it may have made some doctors reluctant to make full use of new developments and some patients to seek appropriate treatment. There has been a gradual change but perhaps some elements of this attitude still persist. I remember some 20 years ago spending a week observing the work of the asthma clinic at the Maudsley Hospital through the kindness of Dr Denis Leigh. My impressions were that the standard of general medical care given to the patients was very high but that the methods of psychotherapy used were too time consuming to be used in most hospitals for such a common disease.

One method which did for a time receive considerable interest was hypnosis. I myself took part in the first attempted clinical trial of hypnosis in children with the help of Dr Charles Burns, the pioneer of child psychiatry in Britain. ${ }^{14}$ Neither this nor later studies showed convincingly successful results but there remained an impression that some patients did benefit. My own interest was not sustained, partly because I found the method laborious and time consuming.

\section{Breathing exercises and special schools}

For many years a popular publication on the subject of asthma was a small booklet of instructions on breathing exercises produced for the Asthma $\stackrel{\infty}{\rightarrow}$ Research Council by Dr James Livingstone. These exercises were aimed at relaxed breathing with use of the diaphragm. Many children received instruction on breathing that probably had limited value but was certainly preferable to unreasonable prohibitions relating to exercise.

The availability of more effective drug treatment 
has reduced interest in physiotherapy. Some of the larger local education authorities maintained special schools, both day and residential, which from about 1950 to 1970 accepted many asthmatic children. Most of these schools were originally opened for "delicate" children. Such children might have been suffering from anything from simple malnutrition to primary tuberculosis, while other schools were devoted entirely to specific physical handicaps such as rheumatic heart disease.

In recent years the number of asthmatic children admitted to such special schools has greatly diminished, their places often being taken by children classified as "maladjusted." With the increasing effectiveness of medical treatment the aim has been more and more to maintain children with asthma at normal schools and to allow as little interference as possible with their education and their ability to earn a living in the future. There has also been some change in the general attitude to exercise. Much, of course, has been written about exercise-induced asthma but the interest is mainly physiological and sport is now generally encouraged.

\section{Special clinics for asthma}

Thirty years ago special clinics for asthma were uncommon. Those that existed did so usually because some individual physician or paediatrician was particularly interested in the disease. Chest clinics in general were busy with tuberculosis and very few of the chest physicians of that time had an interest in asthma. Diagnosis was uncertain and both adults and children with asthma were frequently classified as suffering from chronic bronchitis and treated with antibiotics. Not until tuberculosis ceased to provide most of the work of chest clinics did asthma receive more attention. Other factors played a part in this development-in particular, the better understanding of pulmonary physiology, the availability of dry spirometers in clinics, and access to departments of respiratory physiology. The other major stimulus was the improvement in treatment. General practitioners were more inclined to seek specialist advice when this would provide help with effective treatment.

Whereas before 1960 asthma clinics were usually run by physicians with an interest in some special aspect such as the allergic or the psychological aspects of the condition, the later clinics tended to be mainly oriented to the therapeutic relief of symptoms, with occasionally a major interest in pulmonary physiology. There has been no expansion in the number of clinics devoted to the immunological or allergic aspects of the disease and probably few clin- ics primarily concerned with psychological aspects still exist.

\section{High-altitude treatment}

Davos in Switzerland was once the favourite resort for the wealthy of England and other countries who suffered from tuberculosis and from other respiratory complaints, including asthma. There were many treatment establishments, some of which are now hotels. English was spoken widely in the shops and hotels. There was an English Church and even a free English library. From about 1950 until 1975 many British children were sent to Davos through arrangements with the British Red Cross Society.

The aerobiology of Davos was studied by Davies throughout one year and compared with that of London. ${ }^{15} \mathrm{He}$ found that the most common airborne allergens were much less frequent in Davos, with the exception of basidiospores, which may be of limited clinical importance. Undoubtedly many children, about two-thirds in my experience, were largely free of asthma while at high altitude.$^{16}$ Many of these might also have done well in institutional conditions in England but some others had already been in special schools at home and failed to improve. They stayed for six months to two years in Davos. Whether the prognosis and the quality of their lives was improved in the long term is uncertain but follow-up in later years showed that about $80 \%$ of them did lead a normal life. ${ }^{17}$ Most were able to take part in active exercise during their period at an altitude of over 1500 metres. Improvements in treatment, particularly the introduction of inhaled steroids, have lead to a great reduction in the use of high-altitude treatment and most of the charities and local authorities who used to support the cost have ceased to do so. The exception is a local charity in Birmingham administered by the West Midlands branch of the Red Cross, which still sends a few children to Font Remeu in the Pyrenees. Davos has changed-there are fewer invalids and far more tourists but very few British visitors except for those on package tours. The English library has gone; the Church is rarely used and has no vicar. A generation of chest physicians who were concerned with high-altitude treatment will, however, remember Davos and its medical staff with respect and affection.

\section{Recent developments}

I recently picked up an old, forgotten copy of Chest Disease edited by Perry and Holmes Sellors and published in $1963 .{ }^{18}$ In the chapter on asthma I found these statements: "Most patients with long- 
standing asthma develop bronchitis"; "chronic anoxic pulmonary heart disease (cor pulmonale) becomes an important, and probably an inevitable, accompaniment of the chronic case in old age." This reflects the current opinion of the pathology of asthma and we owe a debt to Professor Jethro Gough, who as a result of applying the Gough and Wentworth paper section technique was able to show that the usual ideas on the pathology of asthma were mistaken to a large extent. Rereading one of his papers ${ }^{19}$ reminded me both of the clarity of his work and of his likeable and unassuming character. The realisation of the essentially non-destructive pathology of asthma had an important influence on the attitude of clinicians. It made them try harder.

"Recent" is difficult to date in the present context, but 1967 stands out in my mind for several reasons. At this time an entirely new form of treatment, disodium cromoglycate, became available and important papers appeared throwing new light on allergic mechanisms in asthma. The discovery of $\mathrm{IgE}$ by the Ishizakas $^{20}$ and almost simultaneously by Johansson and Bennich, ${ }^{21}$ who recognised a myeloma protein as belonging to a previously unknown class of immunoglobulin (later shown to be virtually identical with reagenic antibody ${ }^{22}$ ), has probably had relatively little impact on treatment in general but may yet have an important effect on the success of specific treatment. The other discovery in 1967 , by Voorhorst and others, ${ }^{23}$ was that house dust mites were the principal source of house dust allergen, and this has had a more direct effect. Curiously, the work of Herman Dekker of Munich, who made similar observations in $1928,{ }^{24}$ was overlooked until the Dutch workers published their findings. The first question about the house dust mite allergen was whether it had clinical significance. ${ }^{25}$ There is now no serious doubt about this. The impact on treatment has, however, been less than was at first hoped. Although a useful reduction in exposure to this allergen is fairly certain to come from admission to hospital or going to a high-altitude resort it is very difficult to alter most domestic environments sufficiently to make any clinical difference to mite-sensitive patients.

It is not quite so easy to date the general introduction of the Vitalograph spirometer for use in chest clinics but this simple instrument made routine assessment of airways obstruction possible for all patients under treatment and, although it could not provide the same frequency of observation as the portable peak flow meter and its cheaper versions, it did in my opinion improve the level of clinical assessment in routine practice. My first experience of spirometry dates back to 1958 and a clinical trial of inhaled hydrocortisone. For this I acquired a low-resistance spirometer with a drum and water seal. It had to be specially made and used with a separate kymograph. After the trial I continued to use this and other more compact but similar machines. All were more cumbersome and time consuming than the Vitalograph so that routine use was difficult.

Thus from about 1967 onwards the conditions existed for a considerable improvement in the treatment of asthma. Chest physicians had both time and resources available. Physiological assessment had greatly improved. New and effective drugs were becoming increasingly available and some at least of the prejudices of the past were being replaced by a more positive attitude towards the treatment of the disease. The only rather disappointing aspect was that advances in basic knowledge had not led to corresponding advances in specific treatment.

\section{Systemic corticosteroids}

The use of corticosteroids in asthma is not "recent" in that it dates back to about 1950 . There was, however, confusion and disagreement about the use of this form of treatment for at least 10 years. Even much later there was was no uniformity of practice in the use of these drugs. This does seem curious since the introduction of steroid treatment has probably done more than anything else to give relief to those suffering from asthma. My own first experience of this treatment was in a schoolboy with chronic intractible asthma to whom I gave depot injections of adrenocorticotrophic hormone with limited benefit. He had had a clear chest radiograph before treatment and within two weeks a further film showed a mid-zone shadow. My first thought was that I had precipitated tuberculosis but in a further week his $x$-ray film was clear again and I was greatly relieved.

We did seem to be unduly conscious of possible ill effects and it was some years before I felt confident enough to publish a paper on long-term steroid treatment in asthmatic children, concluding that considerable improvement in the quality of life could be obtained in most cases by using relatively small oral doses of prednisolone with little clinical evidence of adrenal suppression, only occasional obvious deterioration of growth, and an absence of disastrous events attributable to the treatment. ${ }^{26}$ Two deaths occurred in my series of 56 children and in both cases they were due to asphyxia and bronchial plugging. There is no serious doubt that steroids can be life saving but the effect of their introduction on deaths from asthma would be difficult to show, perhaps because they did not gain 
general acceptance quickly and the doses used were often too low. Of 20 children who died from 1960 to 1980 and had at some time been in my care, only 11 were having any steroid treatment when they died and six of these were probably having no more than $5 \mathrm{mg}$ of prednisolone daily. Even three children who died in hospital received only small doses and all three were in general paediatric wards rather than in respiratory units or intensive care units.

The Medical Research Council controlled trial of cortisone acetate published in $1956^{27}$ had a decidedly discouraging effect on the use of steroids. It seems to me that the MRC's work on asthma was very disappointing and contrasted with the outstanding success of the series of trials of antituberculosis treatment. As late as 1961 a leading article in the British Medical Journal began as follows ${ }^{28}$ : "In the treatment of the asthmatic patient it is worth emphasising again that except in severe cases of status asthmaticus corticosteroids should not be administered until all other kinds of treatment have been tried and failed. They must be given only with a full knowledge of their dangers." Thus there was a strong preoccupation with the side effects of steroids and they were considered by many to be drugs of addiction. The same leading article went on to say, "If steroids are administered with care problems of addiction rarely arise. When they do it is apt to be in children aged 10-12 who have been on treatment for a year or more." This discouraging attitude, although soundly based on scientific and clinical observation, presented to some degree an unbalanced view of the clinical use of steroids in asthma. This fear of addiction and of side effects in longterm use often meant that patients were treated in hospital for acute asthma but "weaned off steroids" before discharge, with the result that on return home they frequently relapsed very quickly and sometimes disastrously.

There were, of course, even at this time some authors, such as Grant, ${ }^{29}$ who took the view that it was obvious that corticosteroid treatment could be of the greatest value in chronic asthma and that difficulty in "weaning" patients from corticosteroids was inevitable when treating a chronic disease with an agent withich suppresses its manifestations but does not cure it. To withhold treatment simply because "weaning" may be difficult was to ignore the natural history of chronic asthma and the mode of action of corticosteroids. Rees and Williams in $1962^{30}$ followed a large group of adult patients for up to four years and concluded that long-term steroid treatment reduced the frequency of status asthmaticus and the number of deaths from asthma. They could attribute no deaths to steroids and felt that the benefits seemed to outweigh the possible risks. Such careful clinical observations led in time to a more liberal and rational attitude.

Status asthmaticus is almost always treated with intravenous hydrocortisone with rehydration and with mechanical ventilation if required, a bronchodilator (most frequently aminophylline) also being given. Over the past 10-15 years there has been a gradual tendency to increase the dose of hydrocortisone, with individual doses every three to six hours rising from $100 \mathrm{mg}$ to $1 \mathrm{~g}$ in many units. More recently these very high doses have been questioned, as indeed has the routine use of hydrocortisone in all cases of severe asthma attack. Corticotrophin has never gained the popularity which once seemed possible, partly because it is inconvenient even in depot form, partly because even the synthetic corticotrophin can occasionally cause allergic reactions, and partly because avoiding adrenal suppression is clearly of little significance if the hypothalamopituitary axis is depressed in its place. The work of Friedman and Strang ${ }^{31}$ showing that children having corticotrophin were less liable to growth suppression than those on prednisolone gave rise to considerable interest but did not have any marked impact on clinical practice.

\section{Disodium cromoglycate}

The introduction of disodium cromoglycate (DSCG) into clinical use represented a quite new therapeutic approach. Both the development of the drug and the life of the man principally responsible for it are worthy of inclusion in any account of the history of the treatment of asthma. It was as a result of the courage and perseverance of Dr R E C Altounyan (fig 3) that the research effort within the pharmaceutical industry was made. ${ }^{32}$ Had life followed its expected pattern Roger Altounyan would have remained in Aleppo in charge of the family hospital set up by his grandfather. His work would have been largely surgical. The ending of the French mandate in Syria resulted in the loss of the hospital and almost all he possessed. He came to England not as a stranger, since he had spent most of his life here and had served in the Royal Air Force during the second world war, but certainly as a poorer man than he had ever been. He took employment with a small pharmaceutical company and began his experiments with derivatives of the plant Ammi visnaga, which yielded khellin, used for respiratory conditions in Eastern Mediterranean countries since ancient times. This small company was bought by Fisons Pharmaceuticals, a company with much greater resources. After some hesitation the company supported and enlarged his research.

The fact that Altounyan himself suffered from 


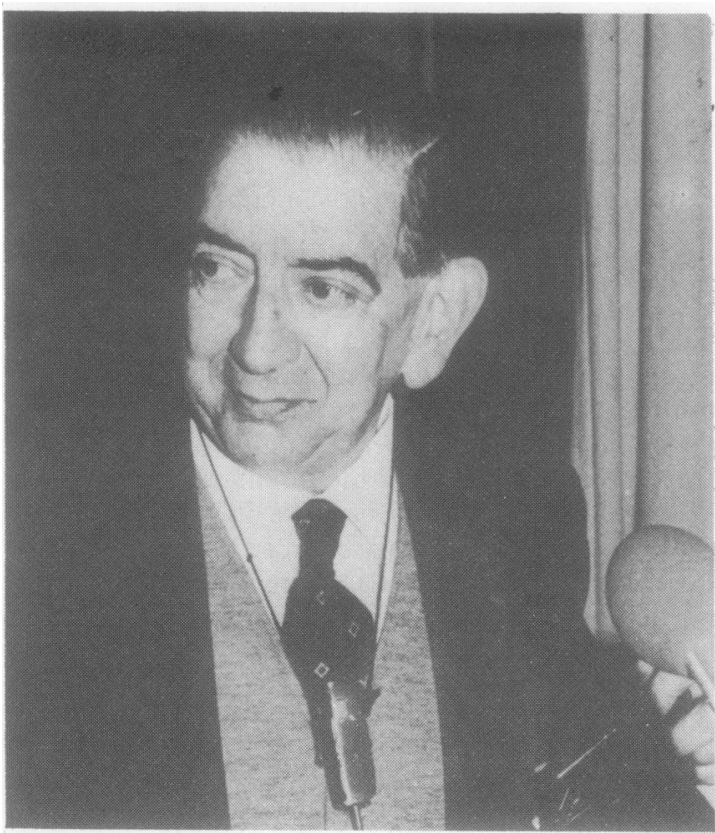

Fig 3 Roger Altounyan.

allergic asthma enabled him to save time and money by carrying out experiments on himself using a series of compounds produced by the chemists. Some of these were inactive and some frankly dangerous. The experiments consisted of attempts to treat, and later to prevent, deliberately provoked attacks. Although DSCG has proved to be one of the safest drugs in medicine many of the experiments carried out in the course of its development were far from safe.

As a boy Altounyan was highly atopic and experienced at first hand, and at considerable expense to his family, all the inadequacy and some of the lack of sympathy with which medicine approached his afflictions in his childhood. It is perhaps his personal and financial misfortune which we have to thank for the development of this drug.

To be concerned with an early clinical trial of an entirely new drug is an exciting and anxious experience, particularly when it is used in children. My personal friendship with Dr Altounyan allowed me to be among the first to use DSCG in children.

The analysis of the results of the double-blind, controlled trial was attended by a degree of tension. Clearly the clinical effect was not so strong that one could guess at the result from knowing the patients. We had to collect and analyse the records carefully in the presence of Altounyan himself. I can still recall our relief and pleasure when the trial showed significant benefit from treatment, and the enjoyable meal that followed. Less enjoyable was the laborious preparation of the paper for publication in the face of understandable editorial caution..$^{33}$

So DSCG came into general use and made a particularly important impact in childhood, reducing by about half the number of children who required long-term steroids. A voluminous body of papers, both clinical and experimental, culminated in the symposium on the mast cell held in Davos in 1979, during which the clinical applications and experimental work on the compound were thoroughly discussed.

Many related compounds have been developed by the pharmaceutical industry. Some have been active orally, and some appear to be many times more active than DSCG in laboratory studies. Strangely, none of these other compounds has so far proved to be so successful and acceptable in clinical use in man.

\section{Inhaled cortiocosteroids}

Like many others in the early days of steroid treatment, I had hoped that local application in the bronchi would be effective in relieving asthma without giving rise to systemic effects. Almost the only available preparation was hydrocortisone hemisuccinate and the solution had to be nebulised by a hand nebuliser with a rubber bulb. It was before the days of pressurised aerosols. My clinical trial showed the failure of this treatment. ${ }^{34}$ My earliest memory of beclomethasone dipropionate (BDP) was of $\mathrm{Dr}$ Harry Morrow Brown giving a short free communication on it at the Eighth European Allergy Congress in Marseilles in 1971. This congress was probably the most enjoyable of many I have attended in the past 30 years. It was superbly organised by Professor Jacques Charpin and there was much medical science of varying quality. Perhaps, however, the importance of the new development in inhaled steroid treatment was not really appreciated. Morrow Brown and his colleagues published their work in due course ${ }^{35}$ and many others, including myself, ${ }^{36}$ followed them and carried out clinical trials with almost uniform success.

The effect of BDP on the clinical management of asthma was considerable and on the whole it improved the quality of treatment over a wider age range than DSCG. There were many young people who with DSCG still required oral steroid treatment to enable them to live a normal life but who could be managed very readily on BDP alone. In older patients this degree of success was not quite so frequent and in some cases BDP only served to reduce the dose of oral steroid. A clinical trial by the Brompton Hospital and Medical Research Council 
in $1974^{37}$ showed that in steroid-dependent adult patients BDP could give significant improvement and allow reduction of the oral dosage. In such patients there was, however, a very high incidence of oropharyngeal candidiasis, particularly with higher doses of BDP such as $800 \mu \mathrm{g}$ daily. In young people and children the occasional occurrence of oropharyngeal thrush has not been of any importance. There has been a general tendency for average doses of BDP to increase since its introduction. Whereas the median daily dose in my own patients was $150 \mu \mathrm{g}$ in 1975 and $200 \mu \mathrm{g}$ in 1976, it rose to $400 \mu \mathrm{g}$ in 1977 and thereafter.

In the United Kingdom I do not believe that chest physicians and paediatricians have been at all anxious about whether inhaled steroids cause adrenal suppression because their clinical experience has been that children sucessfully controlled on inhaled steroids in place of the previous oral steroids lost any cushingoid features, looked well, and were usually found to be growing better. In the United States this satisfaction with the general safety of inhaled steroids and in particular the lack of adrenal suppression in long-term use has been challenged on experimental grounds, ${ }^{38}$ but clinical experience is likely to prove to be of greater weight in determining clinical practice.

For the past 10 years beclomethasone dipropionate has been by far the most commonly used inhaled steroid. Other such drugs with a high degree of local action and minimal systemic action have been developed and may challenge the position of BDP. Betamethasone 17-valerate was also used for its local action initially in dermatology, as was BDP, but although it has been available for just as long and has been shown to be effective in asthma it has not gained the same popularity.

The combined effect of the development of DSCG and BDP was to reduce considerably the number of patients taking oral steroids. With both drugs there was a serious problem of compliance. This did not usually apply during the initial trials but it was certainly a problem in general use. Though good intelligence and family background may help, ${ }^{38}$ the problem of non-compliance is common to many long-continued treatments. There is no doubt that inhaled treatment for asthma, which is more troublesome than oral treatment, has been subject to this difficulty. It could be only partly overcome by clear, repeated instructions and constant encouragement, and by improved design of inhalation devices. The Spinhaler for inhalation of DSCG has remained essentially unchanged since its development by Dr Altounyan with the help of the aeronautical department at Loughborough University, but the equivalent device for inhalation of BDP in powder form was modified several times. Originally inhaled steroids were incorporated in a pressurised aerosol, but as not all patients managed aerosols properly BDP was supplied in powder form in capsules. The Rotahaler device for inhaling these capsules in its original form had several drawbacks. The later and improved model was simpler and more certain in operation. It could be used easily in the dark and had no parts likely to deteriorate quickly.

\section{Bronchodilators}

The first of the synthetic sympathomimetic drugs was isoprenaline, introduced in 1940 and available in a pressurised aerosol after 1950. The general anxiety over the deaths from asthma in the late 1960s resulted in regulations requiring bronchodilator aerosols to be supplied only on prescription by a doctor, whereas until 1967 they could be bought freely in a pharmacy. Aerosol propellants are said to be unlikely to be dangerous in clinical practice ${ }^{40}$ and isoprenaline itself was not suspect when used with a hand bulb nebuliser. A new generation of more specific $\beta$-stimulants introduced from 1967 onwards have almost completely displaced isoprenaline in clinical practice. Those in most frequent use have been salbutamol and terbutaline. In the case of salbutamol there has been a further change in the method of delivery with the development of the powder form in a capsule taken by means of the Rotahaler device used for BDP. As with BDP, this has generally resulted in a higher unit dose, although not necessarily a higher daily dose. For some patients there is an advantage in the powder form since they are not required to synchronise their inhalation with the brief discharge of a pressurised aerosol. The convenience of the pressurised aerosol has, however, ensured its continued popularity for the delivery of bronchodilators.

In hospital practice the use of drugs such as salbutamol solution administered via Wright's nebuliser (or its equivalent) driven either by oxygen or by a small electric air pump has become increasingly popular and to some extent has replaced the intravenous use of the same drugs and even intravenous aminophylline. For many years domestic use of electric nebulisers with bronchodilator solutions such as isoprenaline and later the more specific $\beta$-stimulants was common in European countries. Children who had been treated in Switzerland became accustomed to using such nebulisers on demand if they were awakened by dyspnoea at night or had an attack while playing a vigorous game. Their parents often asked their doctors to prescribe such a device when the children returned home, only 
to be met with a blunt refusal or the problem of obtaining suitable machines in England, particularly on the National Health Service. There has been much more interest in this method of treatment recently and several excellent electric aerosol machines are available. My own practice for almost 30 years was to use isoprenaline (or more recently salbutamol) in a Wright's nebuliser driven by an oxygen cylinder and timed, for children, to half a minute with a sand glass.

The simplest form of administration of any drug is to swallow a small tablet, and oral bronchodilators are still widely used even though much higher doses are required than those given by inhalation, leading to more side effects. The tablets combining ephedrine, aminophylline, and phenobarbitone, once so popular, are no longer much used. Ephedrine has declined greatly in use in recent years and I rarely prescribe it now, whereas before about 1967 I did so very frequently indeed. Rather surprisingly, oral theophylline preparations have in the recent past enjoyed increased popularity, particularly in the form of long-acting tablets. This has been associated with an enthusiasm for measuring blood concentrations of theophylline where such measurements are possible. Theophylline has always been more popular in North America and the newer bronchodilator drugs were not accepted by the United States authorities for some years after they came into general use in the United Kingdom. The popularity of theophylline preparations by mouth seems unlikely to be sustained, but the limited use of aminophylline suppositories may continue despite a national dislike of this form of administration.

\section{Immunotherapy}

Recent years have not been particularly fruitful in respect of important advances in specific treatment of allergic disease despite much new knowledge about immunological mechanisms and mediators of allergic reactions. The main advances have been the greater ease and safety of treatment achieved by modification of extracts of allergens. These extracts have been treated in much the same way as diphtheria toxin is treated to produce a toxoid. The other aim has been to give an equivalent protective effect with smaller doses by delaying absorbtion and destruction of the allergen. The use of oil and silicone emulsions for this purpose proved unsatisfactory owing to their instability and uncertainty in clinical use and the occurrence of local granulomas and chronic ulcers at the site of injection. I tried them all on myself and on a few patients. I had no disastrous results but was not impressed with the benefit. Tyrosine has been used to adsorb allergen extracts and delay release without fear of local ulceration and it has been more successful. The search for a means of modifying allergens to obtain protection without danger goes on.

Another line of research has been the purification of allergens. The most successful practical example of this is the "antigen E" obtained from ragweed by King and Norman in $1962.4^{41}$ It has not, however, shown any convincing advantage over crude extracts in clinical use. ${ }^{42}$ Undoubtedly there is scope for more effective specific treatment. The past has been largely characterised by disappointment that new knowledge of great scientific interest relating to the immunology and physiology of asthma and allergic disease has failed to be translated into new forms of treatment. Surely the day must come when specific treatment will supersede even the best forms of palliative treatment.

\section{References}

${ }^{1}$ Blackley $\mathrm{CH}$. Experimental researches on the causes and nature of hay fever. London: Dawsons of Pall Mall: 1959.

${ }^{2}$ Morrison Smith J. Death from asthma. Lancet 1966;i:1042.

${ }^{3}$ Speizer FE. Doll R, Heaf P. Investigation into the use of drugs preceding death from asthma. $\mathrm{Br} M e d \mathrm{~J}$ 1968; i:339-43.

${ }^{4}$ Stolley PD. Asthma mortality. Why the United States was spared in an epidemic of deaths due to asthma. Am Rev Respir Dis 1972;105:883-90.

5 Anonymous. Death from asthma. Lancet 1968;i:14123.

${ }^{6}$ Oliver G, Schäfer EA. On the physiological action of extracts of pituitary body and certain other glandular organs. J Physiol 1895-6;18:276-9.

${ }^{7}$ Berkhart JB. On bronchial asthma. London: Oxford University Press, 1911.

${ }^{8}$ Cooke F. Asthma. Bristol: John Wright and Sons, 1923.

${ }^{9}$ Dale H. Opening address to the Fourth European Congress of Allergy. Acta Allergol 1960; suppl 7:11-20.

${ }^{10}$ Halpern BM. Les antihistaminiques de synthèse: essais de chemiotherapie des états allergiques. Arch Int Pharmacodyn Ther 1942;68:339-408.

$"$ Noon L. Prophylactic innoculation against hay fever. Lancet 1911;i:1572-3.

12 Maunsell K. Direct test for blocking antibody in treated hay fever. Lancet 1946;ii:199-201.

${ }^{13}$ Williams DA. Classification of asthma and its therapeutic implications. In: The nature of asthma. Midhurst: 1964:85-95.

${ }^{14}$ Morrison Smith J, Burns CLC. The treatment of asthmatic children by hypnotic suggestion. $\mathrm{Br} J$ Dis Chest 1960;54:78-81.

${ }^{15}$ Davies R. R. Climate and topography in relation to aero-allergens at Davos and London. Acta Allergol 1969;24:396-409.

${ }^{16}$ Morrison Smith J. The treatment of asthmatic children away from home. Public Health 1970;84:286-90. 
${ }^{17}$ Morrison Smith J. The use of high altitude treatment for childhood asthma. Practitioner 1981;225:1663-6.

${ }^{18}$ Boland ER. Asthma. In: Perry KMA, Sellors TH, eds. Chest diseases. Vol 2. London: Butterworths, 1963:475-92.

${ }^{19}$ Gough J. Post mortem differences in asthma and chronic bronchitis. Acta Allergol 1961;16:391-9.

${ }^{20}$ Ishizaka K, Ishizaka T, Hornbrook MM. Physicochemical properties of human reagenic antibody IV. Presence of a unique immunoglobulin as a carrier of reaginic activity. J Immunol 1966;97:75-85.

${ }^{21}$ Johansson SGO, Bennich H. Immunological studies of an atypical (myeloma) immunoglobulin. Immunology 1967;13:381-91.

${ }^{22}$ Stanworth DR, Humphrey JH, Bennich H, Johansson SGO. Specific inhibition of Prausnitz-Küstner reaction by an atypical human myeloma protein. Lancet 1967;ii:330-2.

${ }^{23}$ Voorhorst R, Spieksma FThM, Varekamp H, Leupen MJ Lyklema AW. The house-dust mite (Dermatophagoides pteronyssinus) and the allergens it produces: identity with house-dust allergen. J Allergy 1967;39:325-39.

${ }^{24}$ Dekker H. Asthma and mites. Munch Med Wochenschr 1928;75:515.

${ }^{25}$ Morrison Smith J, Disney ME, Williams JD, Gochs ZA. Clinical significance of skin test reactions to mite extracts in children with asthma. $\mathrm{Br} \mathrm{Med} J$ 1969;ii:723-6.

${ }^{26}$ Morrison Smith J. Long-term steroid treatment in asthmatic children. Ann Allergy 1965;23:492-6.

${ }^{27}$ Medical Research Council. Controlled trial of effects of cortisone acetate in chronic asthma. Lancet 1956;ii:798-803.

${ }^{28}$ Anonymous. Corticosteroid therapy in asthma. $\mathrm{Br} \mathrm{Med} \mathrm{J}$ 1961;iv:1413-4.

${ }^{29}$ Grant IWB. Corticosteroids in asthma. Lancet 1956;ii:798.

${ }^{30}$ Rees HA, Williams DA. Long-term steroid therapy in chronic intractable asthma. Br Med J 1962;i:1575-9.
${ }^{31}$ Friedman M. Strang LB. Effect of long-term corticosteroids and corticotrophin on the growth of children. Lancet 1966;ii:568-72.

${ }^{32}$ Cox JSG. Review of chemistry, pharmacology, toxicity, metabolism, specific side-effects, anti-allergic properties in vitro and in vivo of disodium cromoglycate. In: Pepys J, Frankland AW, eds. Disodium cromoglycate in allergic airways disease. London: Butterworths, 1970:13-25.

${ }^{33}$ Morrison Smith J, Devey GF. Clinical trial of disodium cromoglycate in treatment of asthma in children. $\mathrm{Br}$ Med J 1968;ii:340-4.

${ }^{34}$ Morrison Smith J. Hydrocortisone by inhalation in children with asthma. Lancet 1958;ii:1248-50.

${ }^{35}$ Morrow Brown H, Storey G, George WHS. Beclomethasone dipropionate: a new steroid aerosol for the treatment of allergic asthma. $\mathrm{Br}$ Med $J$ 1972;i:585-90.

${ }^{36}$ Morrison Smith J. A clinical trial of beclomethasone dipropionate aerosol in children and adolescents with asthma. Clin Allergy 1973;3:249-53.

${ }^{37}$ Brompton Hospital and Medical Research Council Collaborative Trial. Double-blind trial comparing two dosage schedules of beclomethasone dipropionate aerosol in the treatment of chronic bronchial asthma. Lancet 1974;ii:303-7.

${ }^{38}$ Wyatt R, Waschek J, Weinberger M, Sherman B. Effects of inhaled beclomethasone and alternate day prednisone on pituitary-adrenal function in children with chronic asthma. $N$ Eng J Med 1978;299:1387-92.

${ }^{39}$ Gwynn CM, Morrison Smith J. Long-term results with beclomethasone dipropionate aerosol in children with bronchial asthma. Why does it sometimes fail? $\mathrm{Br} \mathrm{J}$ Clin Pharmacol 1977;4:2695-715.

${ }^{40}$ Anonymous. Fluorocarbon aerosol propellants. Lancet 1975 ;ii:1073-4.

${ }^{41}$ King TP, Norman PS. Isolation studies of allergens from ragweed pollen. Biochemistry 1962;1:709-20.

${ }^{42}$ Lichenstein LM, Norman PS, Winkenwerder WL. Ann Intern Med 1971;75:663-71. 